\title{
Rehabilitación protésica en odontopediatría y sus efectos en la modificación conductual de un niño
}

\author{
DOI: $10.5377 /$ alerta.v4i3.10891
}

\begin{abstract}
Alicia Margarita García Guzmán ${ }^{1}$, Stefany María Santos Anaya ${ }^{2}$, Mirna Tatiana Fuentes Caballero ${ }^{3}$, Milena Elizabeth Olmedo Menjívar ${ }^{4}$, Karen Lisseth Arias Comayagua ${ }^{5}$, Oscar Armando Gómez López ${ }^{6^{*}}$

1-6. Facultad de Odontología, Universidad de El Salvador

${ }^{*}$ Correspondencia

$\square$ oscar.gomez@ues.edu.sv

6. (1) $0000-0001-9241-2771$
\end{abstract}

\section{Resumen}

La caries de la temprana infancia puede afectar severamente la dentición primaria que requiere tratamientos complejos y en ocasiones la extracción del diente afectado. Se presenta informe de caso sobre la rehabilitación dental integral de un paciente de 6 años, la evolución de su comportamiento y la mejora en su calidad de vida, autoestima e interacción social. El plan de tratamiento incluyó una fase de adaptación a la consulta odontológica, eliminación de caries, restauración dental, exodoncias y elaboración de dos prótesis removibles. Al inicio del tratamiento presentó temor y rechazo al tratamiento, pero con el avance del proceso rehabilitador odontológico y la evidencia de los resultados, el comportamiento del niño fue de aceptación y colaboración. Su evolución positiva de comportamiento se presentó también en sus relaciones sociales, aumentó la interacción con otras personas y su participación en juegos con otros niños. La rehabilitación protésica contribuyó a recuperar las funciones de masticación y fonación. La renovación de la estética dental produjo un significativo cambio de conducta, mejora en su autoestima con un impacto psicológico positivo en su calidad de vida.

Palabras clave

Prótesis dental, niño, caries dental, odontopediatría

\begin{abstract}
Early childhood caries can severely affect the primary dentition requiring complex treatments and sometimes the extraction of the affected tooth. A case report is presented on the comprehensive dental rehabilitation of a 6-year-old patient, the evolution of her behavior and the improvement in her quality of life, self-esteem and social interaction. The treatment plan included a phase of adaptation to the dental consultation, elimination of cavities, dental restoration, extractions and elaboration of two removable prostheses. At the beginning of the treatment, he presented fear and rejection of the treatment, but with the progress of the dental rehabilitation process and the evidence of the results, the child's behavior was one of acceptance and collaboration. The positive evolution of her behavior also appeared in her social relationships, increased interaction with other people and her participation in games with other children. Prosthetic rehabilitation contributed to recovering the functions of chewing and phonation. The renovation of dental aesthetics produced a significant change in behavior, improvement in their self-esteem with a positive psychological impact on their quality of life.

Keywords

Dental prosthesis, child, dental caries, pediatric dentistry
\end{abstract}

\section{Introducción}

Según la Organización Mundial de Salud (OMS), entre el $60 \%$ y $90 \%$ de escolares a nivel mundial poseen caries ${ }^{1}$. En El Salvador, la Encuesta Nacional de Salud Bucal, año 2016-2017, determinó que el 63,25 \% de niños de 6 a 12 años presentó caries en dentición permanente; $y$ a los 12 años la prevalencia era del 93,09\%², coincidiendo con lo reportado por la OMS a nivel mundial. a

ACCESO ABIERTO

Prosthetic rehabilitation in pediatric dentistry and its effects on the behaviour of a child

Citación recomendada: García Guzmán AM, Santos Anaya SM, Fuentes Caballero MT, Olmedo Menjívar ME, Arias Comayagua KL, Gómez López OA. Rehabilitación protésica en odontopediatría y sus efectos en la modificación conductual de un niño. Alerta.2021;4(3):119-125. DOI: $10.5377 /$ alerta.v4i3.10891

Recibido:

19 de julio de 2021

Aceptado:

20 de julio de 2021

\section{Publicado:}

26 de julio de 2021

\section{Contribución de autoría:} WMVP': redacción del manuscrito. MLDDC ${ }^{2}$, GEBE³. análisis de los datos y redacción del manuscrito.

\section{Conflicto de intereses:}

Los autores declaran no tener ningún tipo de conflicto de interés. 
La caries de la temprana infancia causa destrucción dental severa, daño pulpar e infecciones que pueden provocar dolor intenso, exigiendo realizar tratamientos complejos y en algunos casos la extracción del diente afectado, alterando la estética, fonación, masticación, nutrición, erupción de dientes permanentes, aparición de hábitos orales nocivos, mal funcionamiento de la articulación temporomandibular, que en conjunto deterioran la calidad de vida del infante ${ }^{3}$. La pérdida prematura de dientes primarios, sobre todo anteriores, origina problemas emocionales, psicológicos y sociales; afecta la confianza del niño, perjudicando su autoestima. Por ello es imperante reestablecer protésicamente los órganos dentales perdidos, para contribuir al correcto desarrollo de los maxilares y prevenir el aparecimiento de alteraciones emocionales y de comportamiento en el niño ${ }^{4}$.

Por estas razones se presenta el informe de caso sobre la rehabilitación dental integral de un paciente de 6 años y cómo esto contribuyó a mejorar su calidad de vida.

\section{Presentación del caso}

Niño de seis años referido a la clínica de odontopediatría de la Universidad de El Salvador, por caries extensa en todos sus dientes, sin antecedentes médicos, familiares ni personales relevantes. El tratamiento odontológico previo se limitó a profilaxis dental.

La madre expresó que debido a la apariencia de sus dientes anteriores, el niño tenía una conducta introvertido y poco sociable.

\section{Examen clínico}

Al examen clínico extraoral presentó configuración cefálica braquifacial y perfil facial convexo con tercio inferior disminuido. En el examen clínico intraoral se identificaron únicamente dientes primarios, todos afectados por caries, mala higiene bucal, eritema generalizado en encía marginal y papilar, restos radiculares del primer molar superior derecho, exposición radicular completa del canino inferior izquierdo, primer y segundo molar inferior derechos y pérdida prematura de los molares inferiores izquierdos (Figura 1).

\section{Examen radiográfico}

Se observan elementos radiopacos correspondientes a restos radiculares del primer molar superior derecho, de los incisivos laterales superiores, del primer molar inferior izquierdo y molares inferiores derechos. Los incisivos centrales superiores, canino supe- rior derecho, segundo molar superior derecho y primer molar superior izquierdo presentan áreas radiolúcidas correspondientes a lesiones cariosas, sin involucramiento pulpar. (Figura 2)

El canino superior izquierdo, segundo molar superior izquierdo y canino inferior derecho presentan áreas radiolúcidas correspondientes a lesiones cariosas con involucramiento pulpar.

\section{Diagnóstico clínico}

Caries de la temprana infancia severa; gingivitis marginal y papilar generalizada inducida por biopelícula bacteriana; necrosis pulpar de canino inferior derecho y canino y segundo molar superior izquierdo; exposición radicular completa del canino inferior izquierdo, restos radiculares del primer molar superior derecho y del primer y segundo molar inferior derechos y pérdida prematura de los molares inferiores izquierdos.

\section{Intervención terapéutica}

El plan de tratamiento inició con adaptación del niño al consultorio odontológico utilizando la técnica «decir, mostrar y hacer» ${ }^{5}$. Se orientó sobre el funcionamiento del sillón odontológico, instrumental y ejecución de procedimientos.

Se instruyó a la madre y al paciente sobre la técnica de cepillado dental de Fones ${ }^{6}$ y uso del hilo dental. Con esta técnica se consigue la remoción de la biopelícula dental, se masajean las encías, se ejercita una higiene completa y se adquiren conocimientos sobre el cuidado bucal. Posteriormente se eliminaron la lesiones cariosas y se efectuó la restauración dental.

Se reconstruyeron los incisivos centrales superiores, el canino superior derecho y el primer molar izquierdo con resina compósita. Se realizó pulpectomía al canino superior izquierdo, al segundo molar superior izquierdo y al canino inferior derecho; los segundos molares superiores y el canino inferior derecho se restauraron con cemento de ionomero de vidrio para reconstrucción dental y el canino superior izquierdo con un restauración de resina compósita en forma de domo para evitar interferir con la estabilidad de la prótesis inferior. No se ejecutó tratamiento en incisivos laterales superiores ni incisivos inferiores, ya que exfoliaron.

Se efectuó exodoncia de primer molar superior derecho, canino inferior izquierdo, primer y segundo molar inferior derechos. Posteriormente, se formó tejido fibroso en el área del canino inferior izquierdo (Figura 3b), que fue extirpado quirúrgicamente. 


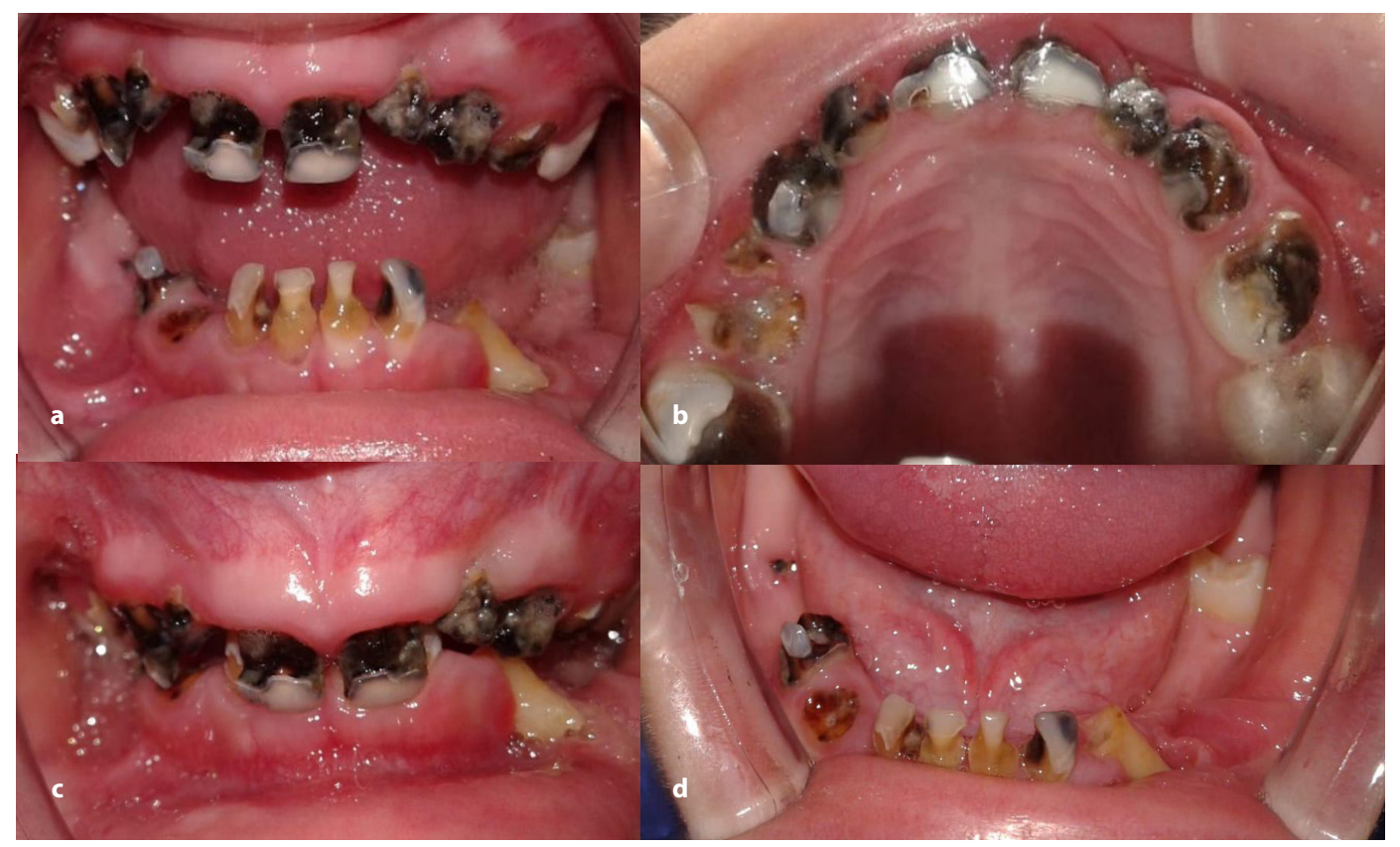

Figura 1. Condiciones dentales del paciente antes de iniciar el tratamiento odontológico. 1a. Arcadas dentales en reposo. 1b. Arcada dental superior con restos radiculares del 5-4. 1c. Arcadas dentales en oclusión. 1d. Arcada dental inferior muestra exposición radicular completa del 7-3, 8-4 y 8-5 y pérdida prematura de 7-4 y 7-5.

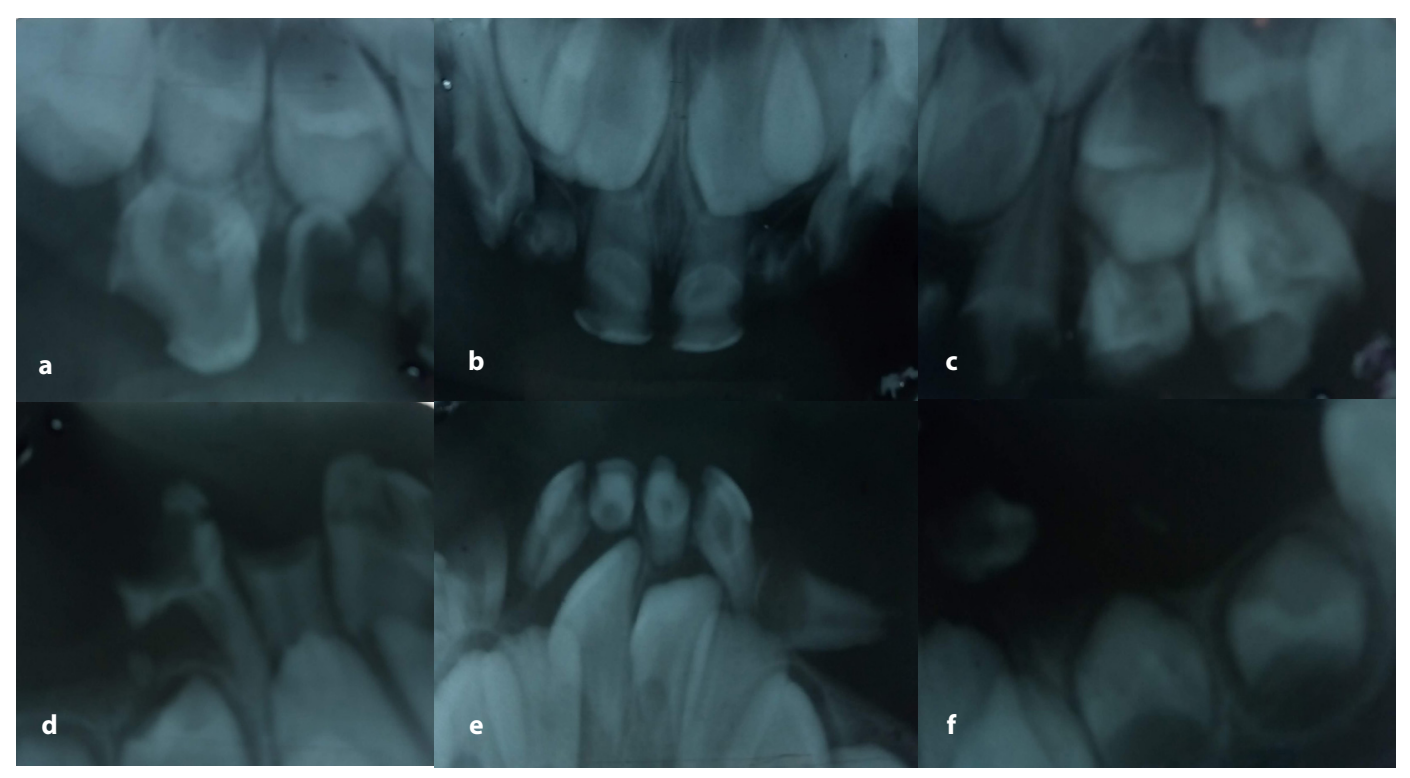

Figura 2. Radiografías dentales periapicales de diagnóstico del paciente antes de iniciar el tratamiento odontológico. 2a. Restos radiculares del 5-4, 5-3, 5-5 con áreas radiolúcidas. 2b. 5-1 y 6-1 con áreas radiolúcidas. 2c. 6-4 con áreas radiolúcidas. 2d. Cuadrante inferior derecho que presenta 7-4. 2e. Área dental anteroinferior. $2 f$. Se evidencian 8-4 y 8-5 y la posición del canino inferior izquierdo.

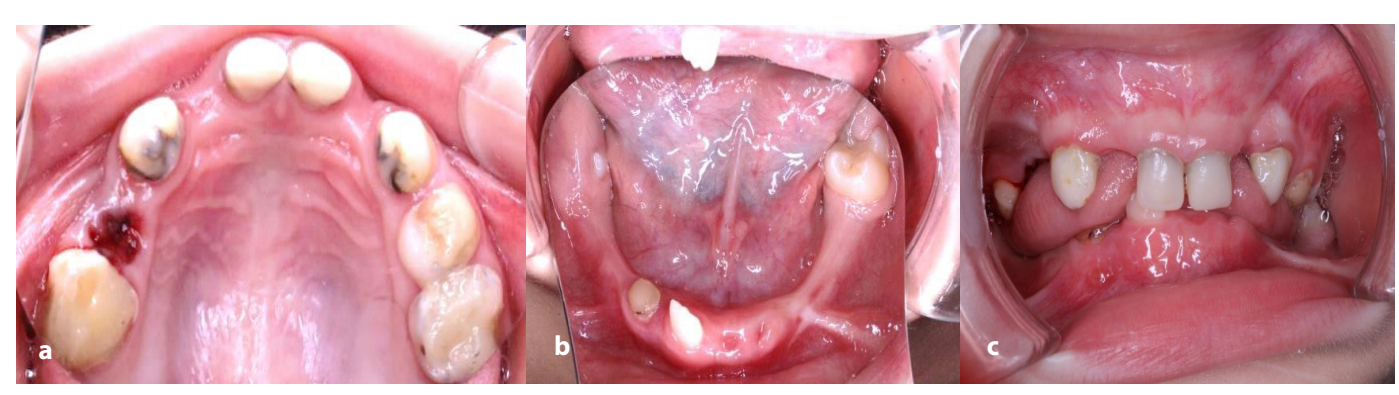

Figura 3. Fase higiénica completada. 3a. Arcada superior sin focos de infección. 3b. Arcada inferior sin focos de infección. Se evidencia el tejido fibroso en el área del canino inferior izquierdo $\mathbf{3 c}$. Arcadas dentales en oclusión. 
La conducta en cada consulta fue descrita a través de la escala de Frankl ${ }^{7}$, que utiliza cuatro parámetros para especificar el comportamiento (Tabla 1).

El paciente mostró conducta negativa durante las citas iniciales, marcada por timidez y desconfianza hacia el odontólogo. La madre indicó que el niño optaba por no relacionarse con nadie, a excepción de ella, por las burlas que recibía en la escuela debido al estado de su dentadura.

Luego de varias sesiones de adaptación, su conducta fue positiva y su comportamiento fue adecuado; lo que permitió el tratamiento de forma efectiva y segura.
Después del examen bucal y análisis de modelos diagnósticos, se colocaron dos prótesis dentomucosoportadas removibles. Se realizó el protocolo para la confección de ambas prótesis; se probaron en el paciente, se verificó el manejo adecuado y se procesaron en el laboratorio. (Figura 4).

Luego, se verificó la adaptación, retención y estabilidad de las prótesis y se evaluó la fonación de palabras con consonantes «f, r, l, v, s y z». Se indicó a la madre cómo colocarlas, retirarlas y evitar su uso al comer y dormir. Se recomendó la higiene diaria con jabón líquido y agua en la parte externa y únicamente con agua en su parte interna. (Figura 5).

Tabla 1. Clasificación de la conducta del paciente durante cada uno de los procedimientos odontológicos realizados, según la escala de Frankl.

\begin{tabular}{|c|c|c|c|}
\hline $\begin{array}{l}\text { Día de } \\
\text { tratamiento }\end{array}$ & Procedimiento realizado & Actitud & $\begin{array}{l}\text { Tipo de } \\
\text { conducta }\end{array}$ \\
\hline 1 & $\begin{array}{l}\text { Anamnesis, exploración clínica extra e } \\
\text { intraoral. Toma de radiografías }\end{array}$ & $\begin{array}{l}\text { Respondió las preguntas solo a la madre, se mantuvo con la cabeza } \\
\text { baja. }\end{array}$ & 2 \\
\hline 6 & Adaptación a la consulta odontológica & Tímido y temeroso. & 2 \\
\hline 7 & Educación en salud oral y Profilaxis & $\begin{array}{l}\text { Tímido. Inicialmente se negó al tratamiento, luego de la explicación, } \\
\text { colaboró. }\end{array}$ & 2 \\
\hline 15 & Reconstrucción directa de 5-3 & $\begin{array}{l}\text { Mejoró la comunicación con el equipo de trabajo. Rechazó equipo } \\
\text { instrumental rotatorio, pero aceptó el tratamiento manual, aunque } \\
\text { se comportó con temor. }\end{array}$ & 2 \\
\hline 21 & Reconstrucción directa de 5-1 & Aceptó el tratamiento, se mantuvo tímido. & 3 \\
\hline 22 & Reconstrucción de directa 6-1 & $\begin{array}{l}\text { Aceptó el tratamiento. } \\
\text { Se mostró alegre con los resultados del tratamiento. }\end{array}$ & 3 \\
\hline 27 & $\begin{array}{l}\text { Pulpectomía y reconstrucción directa de } \\
6-3\end{array}$ & Colaboró con el tratamiento. & 3 \\
\hline 34 & Obturación S2E4 de 6-4 & Rechazó el tratamiento & 2 \\
\hline 42 & $\begin{array}{l}\text { Pulpectomía y reconstrucción directa de } \\
\text { 8-3 }\end{array}$ & $\begin{array}{l}\text { El niño colabora durante la realización del tratamiento. } \\
\text { Aumentó la comunicación con el equipo de trabajo. }\end{array}$ & 3 \\
\hline 42 & Exodoncia de 7-3 & Temeroso por el uso de anestésico. Rechazó al tratamiento. & 2 \\
\hline 52 & Exodoncia de 8-4 & Actuó tranquilo con el equipo de trabajo. & 3 \\
\hline 116 & $\begin{array}{l}\text { Gingivoplastia cuadrante inferior } \\
\text { izquierdo }\end{array}$ & Rechazó el tratamiento. & 2 \\
\hline 148 & Pulpectomía y reconstrucción de 5-5 & $\begin{array}{l}\text { Temeroso con el instrumental, se inició el proceso de readaptación, } \\
\text { finalmente colaboró. }\end{array}$ & 2 \\
\hline 167 & $\begin{array}{l}\text { Recubrimiento pulpar indirecto y } \\
\text { restauración directa de 6-5 }\end{array}$ & Temeroso, se mantuvieron las técnicas de readaptación. & 2 \\
\hline 169 & Reconstrucción directa de 5-1 y 6-1 & Actuó con entusiasmo y motivación por los resultados. & 3 \\
\hline 182 & Exodoncia de 5-4 & Actuó con temor, pero colaboró con el tratamiento. & 3 \\
\hline 188 & $\begin{array}{l}\text { Toma de impresión de arcada superior e } \\
\text { inferior }\end{array}$ & $\begin{array}{l}\text { Aumentó su motivación, seguridad y entusiasmo con la idea de } \\
\text { poder masticar sin problema y tener sus dientes inferiores. }\end{array}$ & 4 \\
\hline 190 & $\begin{array}{l}\text { Prueba de bases de transferencia u } \\
\text { evaluación de la oclusión }\end{array}$ & Actuó con entusiasmo y seguridad. & 4 \\
\hline 196 & Prueba de las prótesis & & 4 \\
\hline 202 & Entrega de prótesis procesadas & $\begin{array}{l}\text { Colaboró con el tratamiento y aumentó la comunicación con el } \\
\text { equipo de trabajo. }\end{array}$ & 4 \\
\hline
\end{tabular}

Tipo de conducta según la Escala de Frankl7: Tipo 1: definitivamente negativo, Tipo 2: negativo, Tipo 3: positivo, Tipo 4: definitivamente positivo 


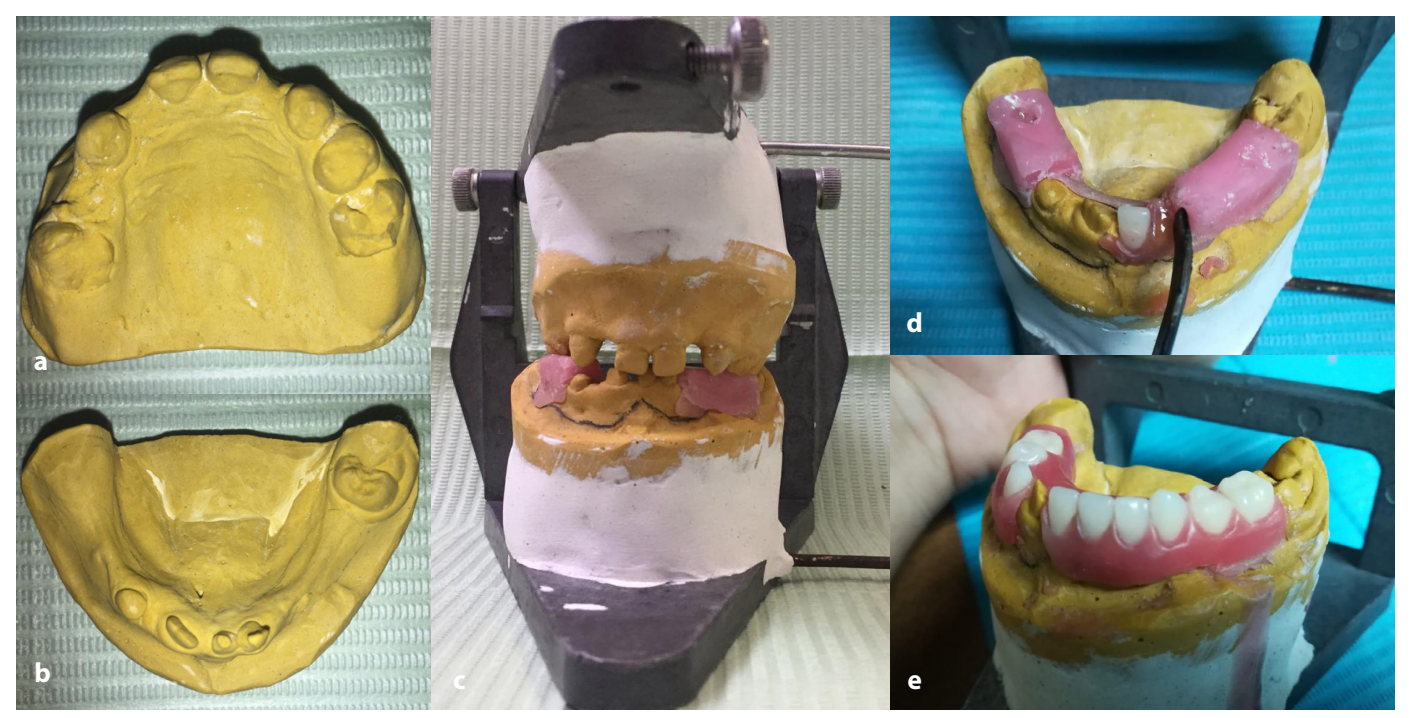

Figura 4. a. Modelo de trabajo superior. b. Modelo de trabajo inferior. Delimitación de extensión de la base de transferencia. c. Modelos montados en articulador. d. Base de transferencia montada en el modelo de yeso inferior con rodete de cera. d. Encerado y tallado en las bases de transferencia caracterizaciones a la encía protésica. Caracterización y colocación en el laboratorio de los dientes artificiales.

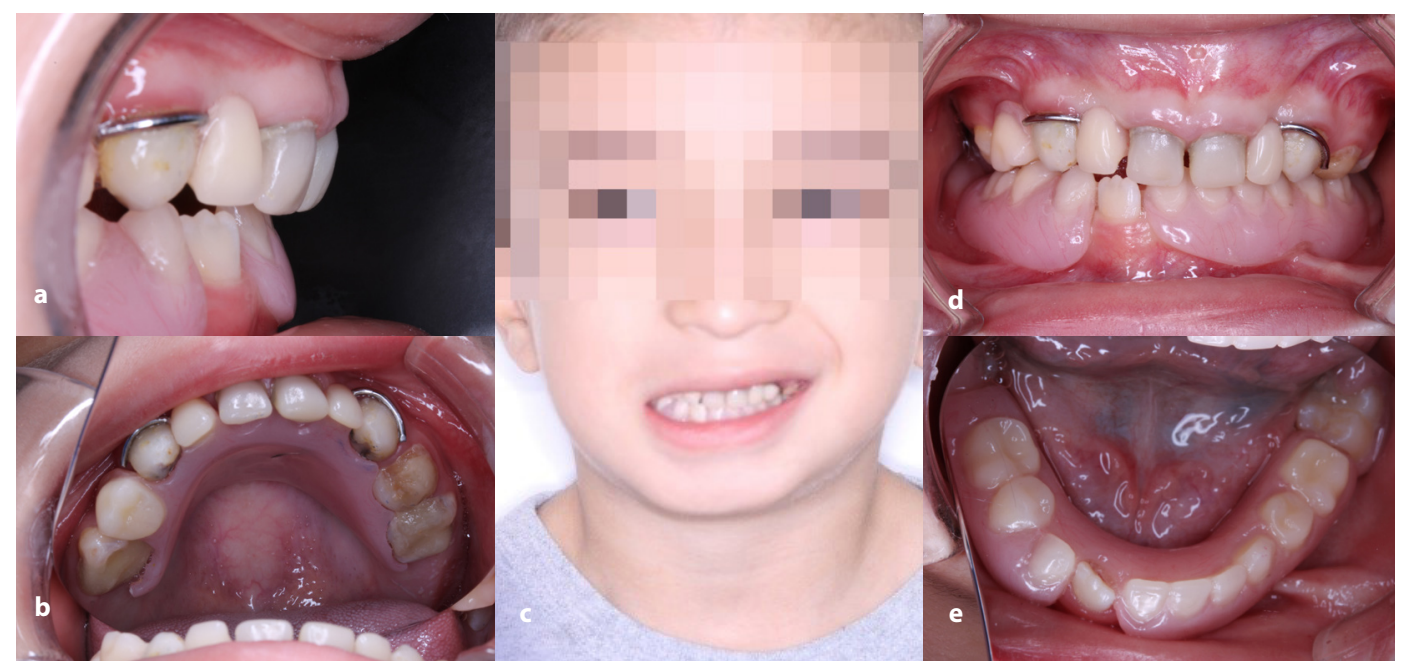

Figura 5. Rehabilitación protésica del paciente. a. Vista lateral de relación de ambas prótesis en oclusión.

b. Prótesis superior colocada en boca. c. Sonrisa del paciente con ambas prótesis en oclusión. d. Vista frontal de ambas arcadas con prótesis en oclusión. e. Prótesis inferior colocada en boca.

Se evaluó su adaptación a las veinticuatro horas posteriores. Se realizaron controles semanales durante el primer mes para examinar la higiene y el mantenimiento de las prótesis. Se realizaron ajustes mensuales por la erupción de los dientes permanentes. Un año después, se cambiaron las prótesis debido al crecimiento del niño.

La evolución en el comportamiento fue satisfactoria. La madre identificó cambios de conducta desde la primera restauración dental, aumentó la interacción con otras personas, la participación en juegos con otros niños, la confianza en sí mismo e inició una dieta con alimentos variados.

En el consultorio odontológico su comportamiento inicial era de timidez. Demostró mejor conducta cuando se restituyó la estética de sus dientes anterosuperiores.
En sus primeras citas evitaba hablar, pero progresivamente su estado de ánimo y su relación con el equipo de trabajo mejoró, finalmente colaboró durante los tratamientos realizados.

\section{Discusión}

Este informe de caso mostró que la rehabilitación de la dentición primaria contribuyó a restablecer las funciones orales, mejorar la nutrición y el comportamiento social del niño, quien se mostraba disgustado con el aspecto de sus dientes, y evitaba hablar y sonreír. Se observaron cambios importantes en la consulta odontológica. La evolución de una conducta negativa a una positiva, confirma la necesidad de incluir en los planes de tratamiento odontopediátricos una 
fase de adaptación, a fin de lograr que el paciente acepte su ejecución y coopere con el odontólogo. También destacó su disposición a colaborar luego de percibir mejoras en la estética de sus dientes, lo que mostró la importancia de la dentadura para verse y sentirse bien.

Estos efectos positivos que se producen al rehabilitar la dentición primaria han sido reportados por Vulićević et al. ${ }^{8}$, Özcan et al. ${ }^{9}$, y Kościelskab et al. ${ }^{10}$, quienes destacan la importancia de devolver la función y estética a la dentición primaria para contribuir al correcto desarrollo sistémico, psicológico, emocional y social en los niños.

Diversos investigadores señalan lo motivos para realizar tratamientos de rehabilitación dental, basados en el desarrollo corporal de los niños. Khinda et al. los recomiendan para mejorar la relación esquelética sagital y vertical durante el crecimiento y desarrollo craneofacial ${ }^{11}$. Dimova-Gabrovska et al. y Dalledone et al. afirman que son importantes para el apropiado establecimiento de la dentición mixta y permanente, contribuyendo al correcto crecimiento y desarrollo maxilofacial y al bienestar psicotsocial del niño ${ }^{12,13}$.

Un factor importante en la rehabilitación protésica es la preservación de dientes, esenciales para la estabilidad y retención de las prótesis, ya que funcionan como pilares que acogen los retenedores. Barrios ${ }^{14}$ afirma que «siempre que sea factible, se debe intentar mantener los dientes primarios».

AlNuaim y Mansoor. ${ }^{15}$ afirman que conservar las raíces de los dientes con daños coronales severos contribuye en la conservación de los rebordes óseos, preserva su altura, reduce las cargas en los huesos, minimiza su proceso de reabsorción, proveen mayor estabilidad protésica y brindan al paciente mayor propiocepción, por lo que las sobredentaduras resultan más cómodas que las prótesis mucosoportadas. Por ello se decidió conservar el canino inferior derecho, realizando una pulpectomía y colocándole una restauración a manera de domo.

Por otra parte, el proceso para realizar una prótesis en niños obedece a los mismos principios establecidos para adultos ${ }^{16}$. Sin embargo, es necesario tener en cuenta que la superficie oclusal de los arcos dentales primarios es plana, por lo que no es necesario establecer las curvas de compensación de Spee y Wilson"1 . La sobremordida horizontal y vertical suele ser de $1 \mathrm{~mm}$ y existe la presencia de espacios fisiológicos interincisivos $^{16}$.

El material de elección para la confección de prótesis pediátricas es la resina acrílica autopolimerizable, que permite realizarles modificaciones para no interferir con la erupción de los dientes permanentes, acompañar el crecimiento y desarrollo del sistema estomatognático hasta la dentición adulta ${ }^{16,17}$

Para establecer las citas de control y observar el funcionamiento de las prótesis en niños es necesario considerar que el establecimiento de la dentición primaria ocurre cerca de los 3 años de vida. De los 3 a los 4 años de edad, los arcos dentales son relativamente estables. A la edad de 5 o 6 años, sus tamaños cambian debido a la fuerza eruptiva de los primeros molares permanentes ${ }^{18}$. Tomando en cuenta la edad del paciente reportado en este informe, los controles se establecieron cada 15 días debido a que estaba iniciando su etapa de recambio dental.

Respecto a la valoración conductual, la escala de Frankl$\left.\right|^{7}$ es práctica, ya que cuenta con criterios precisos para evaluar el comportamiento en un momento determinado, pero no explora las causas que originan una conducta inapropiada en un ambiente odontológico e información necesaria para planificar estrategias de adaptación, por lo que se debe contar con pruebas que permitan obtenerla de forma precisa y completa.

También es necesario indagar objetivamente los cambios producidos en la calidad de vida de un paciente que ha recibido prótesis dentales. Para tal fin se puede recurrir a cuestionarios como el Oral Health Impact Profile (OHIP-14) y adaptarlo a las condiciones que se desean evaluar.

\section{Conclusión}

La rehabilitación dental y colocación de prótesis removibles contribuyó a recuperar las funciones bucales del paciente. Al mejorar su estética dental se produjo un importante cambio de conducta al interactuar con otras personas, mostrando seguridad e interés por conversar y realizar actividades con otros niños, provocándole un impacto psicológico positivo. Todo esto indica un mejoramiento en su autoestima y calidad de vida.

\section{Aspectos éticos}

La presentación de este caso cuenta con la autorización de la madre, quien conoció el objetivo y firmó el consentimiento informado.

\section{Agradecimiento}

Este informe de caso fue apoyado por la Facultad de Odontología de la Universidad de El Salvador, y financiado por las estudiantes del último curso de la carrera de Doctora- 
do en Cirugía Dental que participaron en la resolución del caso. Los autores desean agradecer al personal del Departamento de Odontopediatría y Restaurativa, en especial al Dr. Alejandro Castro, por su asistencia; y a los padres e hijo por haber aceptado participar en el estudio.

\section{Financiamiento}

Los autores declaran no tener fuente de financiamiento.

\section{Referencias bibliográficas}

1. Zhunio K, Urgiles C. Impacto de la caries dental en la calidad de vida en niños de 11 a 12 años de la Unidad Educativa Dolores J Torres, Parroquia Sagrario, Cuenca. KIRU. 2020;17(2):69-74. Disponible en: https:// www.aulavirtualusmp.pe/ojs/index.php/ Rev-Kiru0/article/view/1838

2. Encuesta nacional de salud bucal en la población salvadoreña, año 2016-2017. Facultad de odontología. Universidad de El Salvador. Ministerio de Salud. San Salvador, El Salvador. Disponible en: https://docs. bvsalud.org/biblioref/2021/02/1122047/ encuesta-nacional-11022020-ac.pdf

3. Braga VS, Kramer PF, Ceccato CJ, Ferreira $\mathrm{SH}$. Prosthetic Rehabilitation of a Patient with Severe Early Childhood Caries: A Case Report. JCDR. 2020;14(1):10-12. DOI: 10.7860/JCDR/2020/45091.14118

4. Bledea I, Totolici I, Puscasu C. Oral Rehabilitation in a Child with Anodontia Case Report. Biomed J Sci \& Tech Res. 2018;6(4):5435-5437. DOI: 10.26717/ BJSTR.2018.06.001392.

5. Abanto Alvarez J, Pinto e Carvalho Rezende KM, Bönecker M, Nahás Pires Corrêa F, Salete Nahás Pires Corrêa M. Propuestas no-farmacológicas de manejo del comportamiento en niños. Rev Estomatol Herediana. 2010;20(2):101-106. Disponible en: https://www.redalyc.org/ pdf/4215/421539358009.pdf

6. Merino M, Fajardin N, Osorio J, Mendoza C. Silva P. Carvajal C. López E. Orientaciones técnicas para realizar el cepillado de dientes de niños y niñas que asisten a establecimientos de educación parvularia. Santiago de Chile. Ministerio de Salud. 2016. 21 p. Disponible en: https://diprece. minsal.cl/wrdprss minsal/wp-content/ uploads/2016/12/07.12.2016 OTCEPILLADO-DE-DIENTES-FINAL-DIGITAL.pdf

7. FrankI SN (1962) Should the parent remain with the child in the dental operatory? J Dent Child 29: 150-163.
8. Vulićević Z, Beloica M, Kosanović D, Radović I, Juloski J, Ivanović D. Prosthetics in Paediatric Dentistry. Balk J Dent Med. 2017;21(1):78-82. DOI: 10.1515/ bjdm/2017/0012

9. Özcan, N., Almaz, M.E., Sönmez, l., \& Barış, E. (2016). Satisfaction After Restoring Aesthetics and Function in a Child with Amelogenesis Imperfecta: A Case Report. Meandros Med Dent J. 2016;17(1):98-101. DOI: 10.4274/meandros.2751

10. Kościelska N, Bogucki Z. Clinical factors in prosthodontic treatment of children with genetic defects. Adv Clin Exp Med. 2017;26(6):1005-1012. DOI: 10.17219/ acem/63094

11. Khinda VI, Khinda P, Brar GS, Yadav A. Prosthodontic rehabilitation of a pediatric patient affected with anhidrotic ectodermal dysplasia: A rare case report. J Interdiscip Dentistry. 2016;6:25-8. DOI: 10.4103/2229 5194.188162

12. Dimova-Gabrovska M, Dimitrova D, Mitronin VA. Removable prosthetic treatment in children. Literature review. J of IMAB. 2018;24(3):2172-2176. DOI: 10.5272/ jimab.2018243.2172

13. Dalledone M, de Paiva Bertoli FM, Sponchiado AP, Maris Losso, E, Brancher JA; de Souza JF. Oral rehabilitation with removable dental prosthesis in a six-yearold patient with hypohidrotic ectodermal dysplasia. RSBO. 2017;14(1):44-49. Disponible en: https://www.redalyc.org/ pdf/1530/153052262008.pdf

14. Barrios Z. Rehabilitación en paciente pediátrico. Reporte de caso. MedULA. 2011;20(1):67-72. Disponible en: http:// erevistas.saber.ula.ve/index.php/medula/ article/download/5844/5644

15. AlNuaimi R, Mansoor M. Prosthetic rehabilitation with fixed prosthesis of a 5-year-old child with Hypohidrotic Ectodermal Dysplasia and Oligodontia: a case report. J Med Case Rep. 2019;13(1):329. DOI: 10.1186/s13256-019-2268-4

16. Márquez-Junco MM. Rehabilitación protésica de un niño de 3 años con Displasia ectodérmica hipohidrótica. Rev Odontopediatría Latinoam. 2012;2(1):87-93. Disponible en : $\underline{\text { https:// }}$ www.revistaodontopediatria.org/ ediciones/2012/1/art-10/

17. Hugar SM, Shigli AL, Ravindranath Reddy PV, Roshan NM. Prosthetic rehabilitation of a preschooler with induced anodontia - A clinical report. Contemp Clin Dent. 2011; 2(3):207-10. DOI: 10.4103/0976-237X.86462.

18. Nakata M, Wei S. Guia oclusal en odontopediatria. 1a Edición. Caracas Venezuela: Actualidades Medico Odontologicas Latinoamerica, C.A.; 1989. $104 \mathrm{p}$. 